\title{
Herbicidal efficiency of bromoxynil used independently and in mixtures under conditions of integrated maize cultivation
}

\section{Skuteczność chwastobójcza bromoksynilu stosowanego samodzielnie oraz w mieszaninach w warunkach integrowanej uprawy kukurydzy}

\author{
Hanna Gołębiowska, Renata Kieloch*
}

\section{Summary}

The study was carried out in 2016-2018 on maize field located in Lower Silesia region. Bromoxynil was applied independently and in factory mixture with terbutylazine and each of options was used in a tank mixture with nicosulfuron (Nikosulfuron $040 \mathrm{SC}$ ). Bromoxynil and the examined mixtures were applied in a basic dose and a dose reduced by $33 \%$ but with an oil adjuvant. Bromoxynil applied in the mixture with terbutylazine and nicosulfuron in basic dose and lowered by $33 \%$ (+ adjuvant) controlled weeds to the higher degree than used individually and in the mixture with nicosulfuron only. The highest level of bromoxynil residues in soil samples taken during 8 weeks after application was noted for the object where the bromoxynil was applied with nicosulfuron in the basic dose. In subsequent weeks, level of bromoxynil residues was similar to what was determined for its mixture with nicosulfuron applied in the reduced dose. Bromoxynil decomposed the fastest in soil treated with the mixture (bromoxynil + terbutylazine) + nicosulfuron in dose lowered by $33 \%$.

Key words: application method, reduced dose of herbicide, Zea mays L., weed control, decomposition dynamics

\begin{abstract}
Streszczenie
Badania wykonano na polach kukurydzy zlokalizowanych na Dolnym Śląsku w latach 2016-2018. Bromoksynil aplikowano samodzielnie i w mieszaninie fabrycznej z terbutylazyną, natomiast każdą z opcji zastosowano w mieszaninie zbiornikowej z nikosulfuronem (Nikosulfuron 040 SC). Bromoksynil i badane mieszaniny użyto w dawce podstawowej oraz obniżonej o 33\%, lecz z adiuwantem olejowym. Bromoksynil zastosowany w mieszaninie z terbutylazyną i nikosulfuronem w dawce podstawowej oraz obniżonej o $33 \%$ (+ adiuwant) w większym stopniu niszczył chwasty niż aplikowany samodzielnie oraz w mieszaninie tylko z nikosulfuronem. Najwyższy poziom pozostałości bromoksynilu w próbkach glebowych pobieranych w 8 tygodni po zabiegu stwierdzono dla obiektu, na którym zastosowano go z nikosulfuronem w dawce zalecanej. W kolejnych tygodniach poziom pozostałości bromoksynilu na tym obiekcie był zbliżony do tego, jaki oznaczono dla jego mieszaniny z nikosulfuronem w dawce zredukowanej. Bromoksynil najszybciej uległ rozkładowi w glebie traktowanej mieszaniną (bromoksynil + terbutylazyna) + nikosulfuron w dawce zredukowanej o 33\%.
\end{abstract}

Słowa kluczowe: sposób aplikacji, zredukowana dawka herbicydu, Zea mays L., zwalczanie chwastów, dynamika rozkładu

Instytut Uprawy Nawożenia i Gleboznawstwa - Państwowy Instytut Badawczy

Zakład Herbologii i Technik Uprawy Roli

Orzechowa 61, 50-540 Wrocław

*corresponding author: r.kieloch@iung.wroclaw.pl

ORCID: 0000-0001-7411-1115 


\section{Wstęp / Introduction}

Kukurydza należy do roślin rolniczych wykazujących wysoki potencjał plonotwórczy na różnych typach gleb (z wyjątkiem zdegradowanych), jak i w różnych systemach uprawy, pod warunkiem całkowitego wyeliminowania konkurencyjnego oddziaływania chwastów. Zadanie to przez blisko pięćdziesiąt lat spełniały herbicydy triazynowe zawierające substancje czynne, takie jak: symazyna, atrazyna czy terbutylazyna. Długo oddziaływały na wschodzące chwasty oraz zabezpieczały plantację przed zachwaszczeniem wtórnym, a łączenie ich z adiuwantami, jeszcze bardziej poprawiało ich skuteczność chwastobójczą poprzez zwiększoną przyczepność do powierzchni liści i szybsze wnikanie. Obecnie w uprawie kukurydzy poszukuje się skutecznych metod odchwaszczania bądź to związanych z uprawą międzyrzędową i właściwym pokryciem przez roślinę uprawną, bądź to $\mathrm{z}$ wykorzystaniem chemicznych zabiegów systemowych opartych na mieszaninach kilku substancji czynnych (Abdin i wsp. 2000; Gołębiowska 2011). Dużym zainteresowaniem łączenia ich $\mathrm{w}$ gotowe mieszaniny cieszy się zastosowanie terbutylazyny, jedynej substancji czynnej z grupy triazyn dopuszczonej obecnie do ochrony kukurydzy przed chwastami (Pruszyński i wsp. 2002; Rozporządzenie 2009; Rozporządzenie MRiRW 2013; Týr 2015).

W aspekcie respektowania zasad integrowanej ochrony roślin, tj. minimalizowania skutków chemizacji, zabiegi te powinny uwzględniać systemy dzielenia dawek oraz obniżania łącznej zawartości substancji czynnych wspomagane użyciem adiuwantów. Herbicydy łączone w zabiegach systemowych, poza wysoką efektywnością w niszczeniu chwastów i selektywnością dla odmian kukurydzy, powinny szybko dezaktywować się w środowisku glebowym i nie powodować uodparniania się chwastów (Kucharski i Sekutowski 2007; Adamczewski i Kierzek 2011). Wprowadzanie do praktyki zabiegów systemowych ma wpływ na dynamikę rozkładu herbicydów oraz poziom ich pozostałości w glebie. Aktualnie największy udział w ochronie kukurydzy mają herbicydy sulfonylomocznikowe. Jednak ich wadą jest krótki okres oddziaływania oraz mała skuteczność niszczenia komosy białej, gatunku dominującego w zachwaszczeniu wtórnym kukurydzy. Przedstawicielem tej grupy chemicznej jest nikosulfuron. Łączenie go z bromoksynilem zwiększa spektrum zwalczanych chwastów dwuliściennych o komosę białą i gatunki rdestowate, a dodatek terbutylazyny może znacznie wydłużyć okres oddziaływania i ograniczyć zachwaszczenie wtórne (Ehsas i wsp. 2016).

Celem badań była analiza efektywności chwastobójczej mieszanin bromoksynilu w zabiegach systemowych z obniżonymi dawkami oraz dynamiki rozkładu pozostałości herbicydu w glebie.

\section{Materiały i metody / Materials and methods}

Badania przeprowadzono w latach 2016-2018, w Zakładzie Herbologii i Technik Uprawy Roli Instytutu Uprawy Nawożenia i Gleboznawstwa - Państwowego Instytutu Badawczego we Wrocławiu na polach indywidualnego gospodarstwa rolnego w Zagródkach koło Wrocławia. Wykonano je w kukurydzy uprawianej na czarnej ziemii wrocławskiej zakwalifikowanej do kompleksu pszennego bardzo dobrego, o wysokiej zawartości próchnicy (3,6\%) i pH 6,3. Przed siewem kukurydzy i założeniem doświadczeń na całym polu przeprowadzano $\mathrm{w}$ pełnym zakresie zabiegi uprawowe oraz stosowano nawożenie zgodnie z zaleceniami agrotechnicznymi.

Bromoksynil stosowany w doświadczeniach występował samodzielnie (herbicyd Emblem 20 WG) oraz łącznie z terbutylazyną (herbicyd Zeagran 340 EC). W celu zwiększenia spektrum zwalczanych chwastów stosowano je z dodatkiem nikosulfuronu (Nikosulfuron 040 SC). Zarówno Emblem 20 WG, jak i Zeagran 340 EC oraz ich mieszaniny $\mathrm{z}$ nikosulfuronem aplikowano jednorazowo $\mathrm{w}$ pełnych oraz obniżonych o $1 / 3$ dawkach. W przypadku aplikacji obniżonych dawek, do badanych mieszanin dodawano adiuwant Atpolan $80 \mathrm{EC}$ w dawce 1,5 1/ha (olej SN 76\%). Charakterystykę ocenianych środków i ich dawki podano w tabeli 1.

Zabiegi wykonano opryskiwaczem plecakowym „Gloria" wyposażonym w 4 dysze TeeJet XR 11003-VS, pracującym ze stałym ciśnieniem roboczym $0,25 \mathrm{MPa}$ i wydatkiem cieczy użytkowej wynoszącym $250 \mathrm{l} / \mathrm{ha}$. Herbicydy i ich mieszaniny aplikowano w fazie 3-4 liści kukurydzy, gdy chwasty znajdowały się w fazie $1-5$ liści. Skuteczność działania herbicydów i ich mieszanin określano zgodnie z metodyką przyjętą w herbologii (Domaradzki 2001).

Zniszczenie chwastów na poletkach oceniono szacunkowo, porównując stan zachwaszczenia z nieopryskiwaną kontrolą po upływie 3 tygodni od zabiegu.

Zachowanie się bromoksynilu w środowisku glebowym badano na podstawie dynamiki jego rozkładu i poziomu pozostałości w całym sezonie wegetacyjnym. W wyznaczonych odstępach czasowych $(0,1,2,3,4,6,8,10,14$ tygodni od opryskiwania) pobierano próby glebowe z poletek (z warstwy $10-20 \mathrm{~cm}$ ) za pomocą laski glebowej i przenoszono je do pojemników. Z poletka o powierzchni $25 \mathrm{~m}^{2}$ pobierano 5 próbek. Wszystkie próbki pobrane z poletka połączono, wymieszano na tacy, oczyszczono $\mathrm{z}$ ciał obcych i wstępnie rozdrobniono. Z próby ogólnej pobrano $350 \mathrm{~g}$ gleby i umieszczono w szczelnie zamkniętym pojemniku. Wszystkie pobrane próby przechowywano w zamrażarce w temperaturze $-20^{\circ} \mathrm{C}$ (okres przechowywania do 90 dni). Każdą próbkę rozmrożono i rozdrobniono w młynku do gleby, a następnie przesiano przez sito. Po przesianiu gleby i odrzuceniu części szkieletowych pobrano 100 g gleby do badań laboratoryjnych. Ekstrakcję pozostałości bromoksynilu z próbki glebowej wykonano acetonem na 
Tabela 1. Charakterystyka herbicydów

Table 1. Charasteristic of herbicides

\begin{tabular}{l|c|c|c}
\hline $\begin{array}{c}\text { Herbicyd } \\
\text { Herbicide }\end{array}$ & $\begin{array}{c}\text { Substancja czynna } \\
\text { Active substance }\end{array}$ & $\begin{array}{c}\text { Dawka podstawowa (DP) } \\
\text { Basic dose }\end{array}$ & $\begin{array}{c}\text { Dawka obniżona (2/3 DP) } \\
\text { Reduced dose }\end{array}$ \\
\hline Emblem 20 WG & bromoksynil - bromoxynil $200 \mathrm{~g} / 1$ & $1,5 \mathrm{l} / \mathrm{ha}$ & $1,01 / \mathrm{ha}$ \\
\hline Nikosulfuron 040 SC & nikosulfuron - nicosulfuron $40 \mathrm{~g} / 1$ & $1,0 \mathrm{l} / \mathrm{ha}$ & $0,751 / \mathrm{ha}$ \\
\hline Zeagran 340 EC & $\begin{array}{c}\text { bromoksynil + terbutylazyna } \\
\text { bromoxynil + terbutylazine } 250+90 \mathrm{~g} / 1\end{array}$ & $0,7 \mathrm{l} / \mathrm{ha}$ & $0,51 / \mathrm{ha}$ \\
\hline
\end{tabular}

aparacie Dionex $350 \mathrm{AS}$ w temperaturze $40^{\circ} \mathrm{C}$, z ciśnieniem 0,2 MPa. Następnie ekstrakt odparowano, a pozostałą suchą masę rozpuszczono $\mathrm{w} 10 \mathrm{ml}$ acetonu. $\mathrm{Z}$ powstałego roztworu pobrano $2 \mathrm{ml}$ i poddano procesowi derywatyzacji. Pozostałości nierozłożonych substancji czynnych herbicydów analizowano ilościowo i jakościowo, stosując technikę wysokosprawnej chromatografii gazowej z detekcją wychwytu elektronów (GC/ECD) (Kalitowska i Kucharski 2017).

W statystycznym opracowaniu wyników zastosowano analizę wariancji dla doświadczeń polowych w układzie losowanych bloków. Istotność różnic testowano wykorzystując półprzedział ufności Tukey’a przy poziomie istotności $\alpha=0,05$. Obliczenia wykonane zostały za pomocą programu Statgraphic.

\section{Wyniki i dyskusja / Results and discussion}

Warunki pogodowe w latach 2015-2018 sprzyjały prawidłowemu rozwojowi i dojrzewaniu kukurydzy. Łagodne i bezśnieżne zimy oraz korzystny rozkład temperatur i opadów na przedwiośniu, powtarzające się w latach badań, wpłynęły na wczesny siew kukurydzy, już na przełomie I i II dekady kwietnia (tab. 2). Sumy efektywnych temperatur oraz równomierne uwilgotnienie $\mathrm{w}$ całym sezonie wegetacyjnym pozwoliły uzyskać pełną dojrzałość ziarna już pod koniec września.

Wyniki badań uzyskane z doświadczeń polowych prowadzonych na czarnych ziemiach, gdzie stosowano prawidłowy płodozmian oraz uprawę kukurydzy w oparciu o orkę, świadczą o możliwości efektywnego niszczenia zbiorowisk chwastów z dominacją chwastnicy jednostronnej i komosy białej, herbicydami lub ich mieszaninami stosowanymi w obniżonych dawkach (tab. 3). Możliwa jest wysoka skuteczność zwalczania chwastów jedno- i dwuliściennych środkami Emblem 20 WG i Zeagran 340 EC, łącznie z herbicydem Nikosulfuron $040 \mathrm{SC}$ w dawkach obniżonych o 1/3. Najlepsze działanie chwastobójcze na tych glebach wykazała mieszanina herbicydów Zeagran 340 EC i Nikosulfuron $040 \mathrm{SC}$ z adiuwantem zarówno w dawkach zalecanych, jak i obniżonych. Podobne zależności uzyskano dla herbicydów zawierających imazamoks oraz foramsulfuron
(Pannacci i wsp. 2006; Pannacci 2016). Decyzję o dodatku adiuwanta do badanych mieszanin herbicydów podjęto w oparciu o doniesienia literaturowe zalecające stosowanie tych środków w razie niekorzystnego przebiegu pogody lub w przypadku stosowania ograniczonych dawek herbicydów (Idziak i Woźnica 2016). Adiuwanty wspomagają działanie herbicydów poprzez poprawę ich retencji, zapobieganie krystalizacji herbicydów na powierzchni liści oraz wzmocnienie absorbcji substancji czynnych do komórek roślinnych. Pozytywne wyniki uzyskane z doświadczeń dają podstawę do propagowania badań nad obniżaniem dawek herbicydowych na plantacjach o niskim nasileniu zachwaszczenia, na co wskazują również prace innych autorów (Hruszka 2003; Vasileiadis i wsp. 2016).

W prezentowanych badaniach notowano średnie nasilenie chwastnicy jednostronnej w ilości $28 \mathrm{szt} . / \mathrm{m}^{2}$, nieco niższe komosy białej w ilości $15 \mathrm{szt} . / \mathrm{m}^{2}$, niewielkie fiołka polnego i przetacznika perskiego wynoszące odpowiednio 8 i 6 szt. $/ \mathrm{m}^{2}$ oraz pojedyncze egzemplarze rdestu plamistego (tab. 3). W sytuacji takiego nasilenia gatunków jednoi dwuliściennych możliwość uzyskania zadowalającego efektu chwastobójczego z zastosowaniem badanych herbicydów sprawdziła się jedynie w przypadku łączenia ich $\mathrm{z}$ herbicydem Nikosulfuron $040 \mathrm{SC}$ z dodatkiem adiuwanta, użytych w dawkach nawet o $33 \%$ niższych niż zalecane. Na obiektach, na których uzyskano najlepszy efekt chwastobójczy w czasie 3-4 tygodni od aplikacji herbicydów, zaobserwowano również najmniejsze zachwaszczenie wtórne tymi gatunkami w okresie wiechowania kukurydzy. Zadowalający efekt chwastobójczy uzyskany w całym sezonie wegetacyjnym przełożył się na uzyskanie wysokich plonów ziarna, o wysokiej masie 1000 ziaren. Po zastosowaniu zarówno pełnej, jak i obniżonej dawki mieszaniny herbicydów Zeagran 340 EC i Nikosulfuron $040 \mathrm{SC}$ z adiuwantem uzyskano wzrost odpowiednio o $69 \%$ i $35,6 \%$ w porównaniu z obiektem kontrolnym prowadzonym bez ochrony herbicydowej. Wpływ zachwaszczenia na wysokość i strukturę plonu ziarna podkreślali w swych doniesieniach Furlan i wsp. (2017) oraz Szulc i wsp. (2017).

$\mathrm{Na}$ proces zanikania substancji czynnych herbicydów składają się dwa zasadnicze etapy. Pierwszy to rozkład chemiczny i mikrobiologiczny, w trakcie którego następuje 
Tabela 2. Warunki pogodowe w okresie doświadczalnym

Table 2. The weather conditions during experimental period

\begin{tabular}{|c|c|c|c|c|c|c|c|c|c|c|c|c|c|}
\hline \multirow{2}{*}{$\begin{array}{c}\text { Czynnik } \\
\text { pogodowy } \\
\text { Weather factor }\end{array}$} & \multirow{2}{*}{$\begin{array}{l}\text { Rok } \\
\text { Year }\end{array}$} & \multicolumn{12}{|c|}{ Miesiące - Months } \\
\hline & & I & II & III & IV & V & VI & VII & VIII & IX & $X$ & XI & XII \\
\hline $\mathrm{T}\left[{ }^{\circ} \mathrm{C}\right]$ & 2016 & $-1,1$ & 3,8 & 4,4 & 8,7 & 15,1 & 18,5 & 19,5 & 18,1 & 16,4 & 8,3 & 3,8 & 1,5 \\
\hline $\mathrm{O}[\mathrm{mm}]$ & 2010 & 19,1 & 75,9 & 38,3 & 74,2 & 20,7 & 76,3 & 89,8 & 41,1 & 64,9 & 67,0 & 102,3 & 25,0 \\
\hline $\mathrm{T}\left[{ }^{\circ} \mathrm{C}\right]$ & 2017 & $-3,4$ & 0,6 & 6,9 & 8,0 & 14,1 & 18,5 & 19,1 & 19,7 & 16,6 & 9,0 & 5,8 & 2,4 \\
\hline $\mathrm{O}[\mathrm{mm}]$ & 2017 & 11,8 & 32,4 & 28,7 & 81,0 & 22,5 & 85,9 & 106,1 & 53,7 & 45,6 & 50,2 & 58,9 & 36,2 \\
\hline $\mathrm{T}\left[{ }^{\circ} \mathrm{C}\right]$ & 2018 & 2,7 & $-1,8$ & 1,4 & 13,4 & 17,0 & 18,7 & 19,9 & 21,1 & 16,0 & 10,7 & 5,5 & 2,6 \\
\hline $\mathrm{O}[\mathrm{mm}]$ & 2010 & 15,6 & 17,0 & 9,6 & 20,9 & 40,6 & 111,2 & 54,9 & 11,5 & 54,4 & 32,2 & 42,3 & 40,3 \\
\hline
\end{tabular}

$\mathrm{T}$ - temperatura - temperature, $\mathrm{O}$ - opady - rainfalls

Tabela 3. Skuteczność niszczenia chwastów i wpływ na wysokość plonu kukurydzy

Table 3. Weed control efficacy and impact on yield size of maize

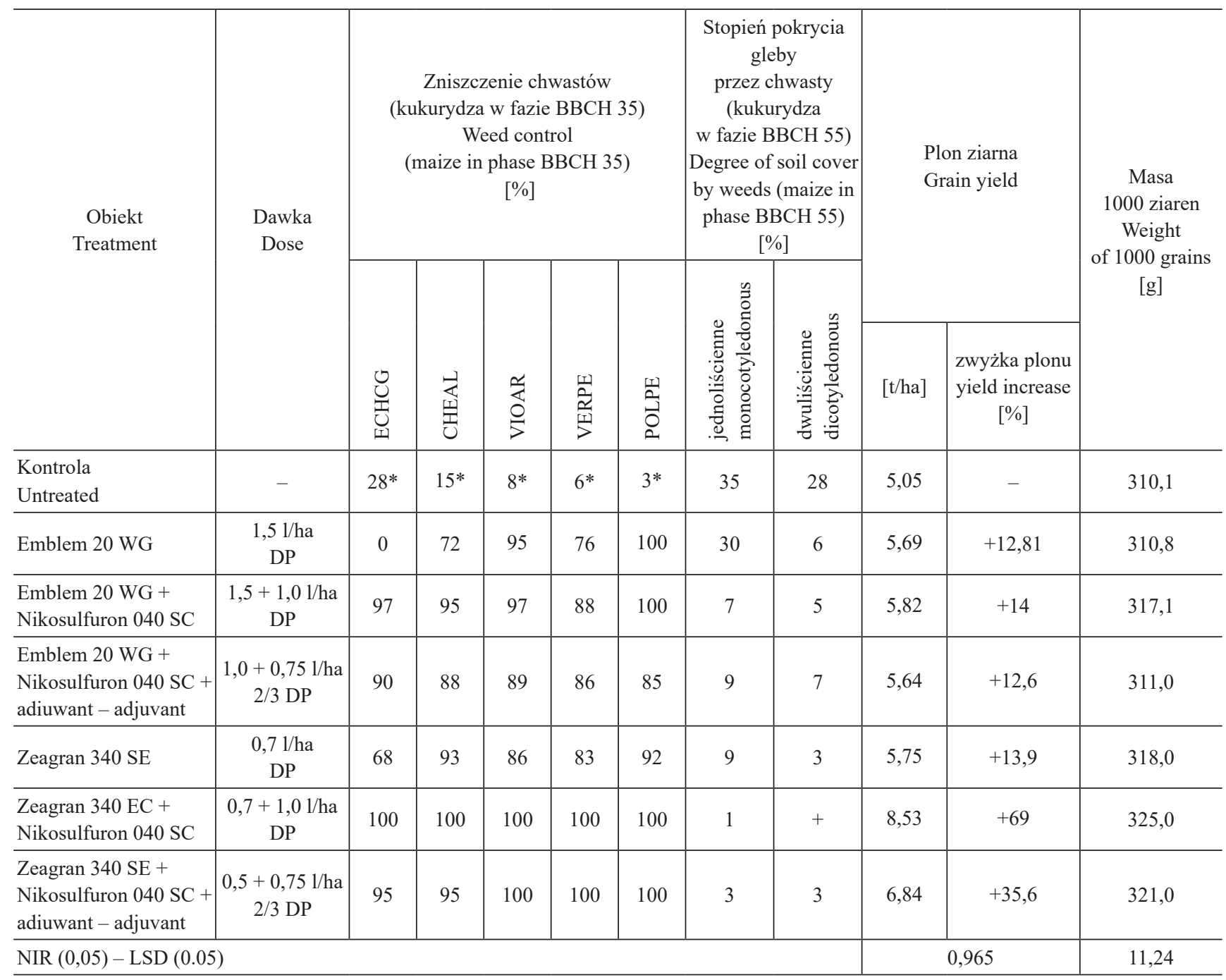

*dla kontroli podano liczbę chwastów [szt. $\left./ \mathrm{m}^{2}\right]$ - for untreated weeds numer is given $\left[\mathrm{pcs} / \mathrm{m}^{2}\right.$ ]

DP - dawka podstawowa - basic dose

ECHCG - Echinochloa crus-galli, CHEAL - Chenopodium album, VIOAR - Viola arvensis, VERPE - Veronica persica, POLPE - Polygonum persicaria

rozpad cząsteczek najpierw do metabolitów, z których część ma działanie biologiczne, a następnie do substancji prostych (woda, dwutlenek węgla, itp.). Drugim jest proces prze- mieszczania w głąb profilu glebowego. Procesy te zachodzą z różną szybkością, jak również szybkość tych zjawisk jest zmienna $\mathrm{w}$ czasie. Jednocześnie substancje czynne są po- 


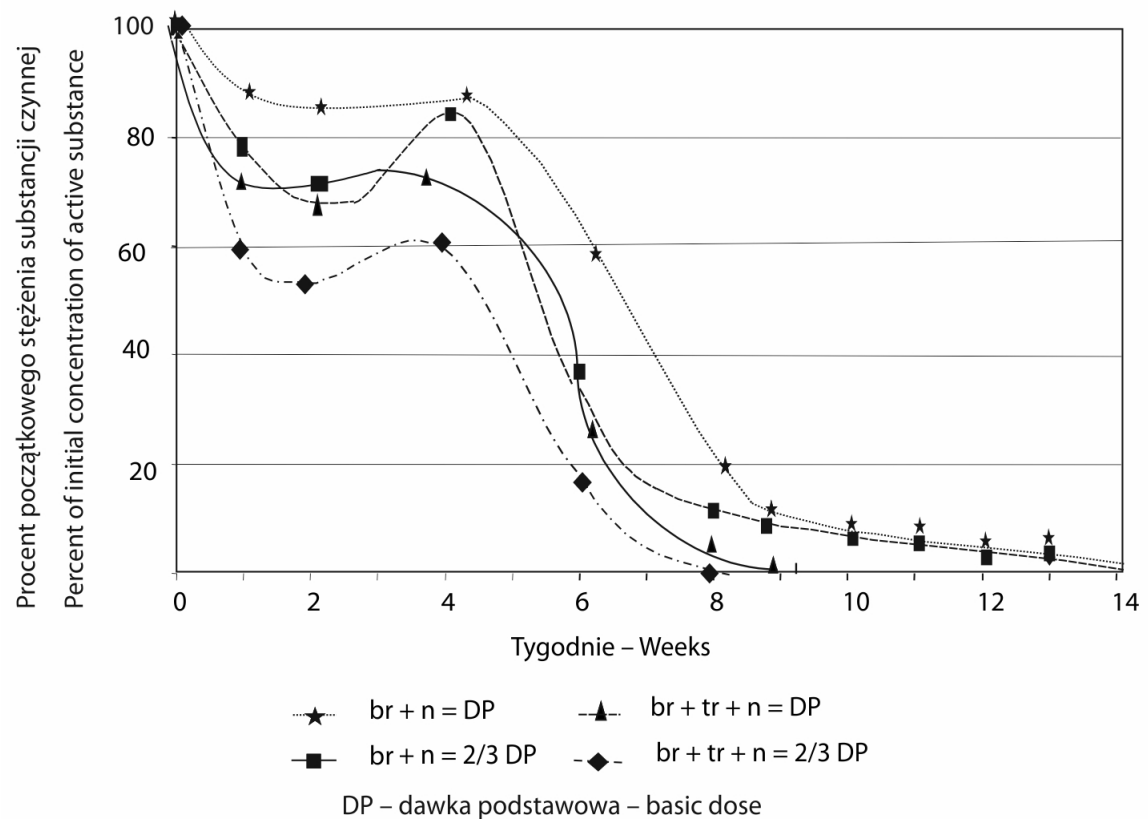

Rys. 1. Dynamika zanikania bromoksynilu w glebie

Fig. 1. Dynamics of bromoxynil decay in soil

bierane przez rośliny uprawne i chwasty. W wyniku tych oddziaływań następuje spadek stężenia substancji czynnych herbicydu w glebie (Sadowski 2009).

Obserwując przebieg krzywych dynamiki zanikania bromoksynilu $\mathrm{w}$ pierwszych dwóch tygodniach po aplikacji, zanotowano spadek stężenia substancji czynnej w glebie, który osiągnął 58\% stężenia początkowego dla obniżonej dawki mieszaniny bromoksynil + terbutylazyna + nikosulfuron oraz $85 \%$ stężenia początkowego dla pełnej dawki bromoksynilu + nikosulfuron (rys. 1). W czwartym tygodniu po aplikacji wystąpił obfity opad, co skutkowało wzrostem zawartości substancji czynnej w próbkach glebowych pobranych z poletek, na których zastosowano obie mieszaniny z dodatkiem adiuwanta. Adiuwanty ograniczają przemieszczanie herbicydu w głąb profilu glebowego, natomiast opady deszczu w powyższym terminie spowodowały wymycie herbicydu do niższej warstwy, tj. 10-20 cm, co skutkowało wzrostem stężenia pozostałości (Kucharski i wsp. 2012). W następnych tygodniach aż do zbioru (około 14 tygodni), stężenie bromoksynilu w glebie systematycznie zmniejszało się. Najszybciej, bo po 8 tygodniach, całkowity rozkład osiągnięto w próbkach pobranych z poletek opryskiwanych mieszaniną bromoksynilu + terbutylazyna + nikosulfuron (+ adiuwant) w dawce zredukowanej. Dwa tygodnie później nie wykryto pozostałości bromoksynilu na obiektach, na których powyższą mieszaninę (bez adiuwantu) zastosowano w dawce podstawowej. Natomiast w przypadku bromoksynilu stosowanego samodzielnie, nawet 14 tygodni po aplikacji, wykrywano niewielkie ilości pozostałości tej substancji, rzędu 1-3\% stężenia początkowego.

Przebieg dynamiki zanikania bromoksynilu wskazuje, że w przypadku pełnej dawki herbicydu, proces ten był nieco wolniejszy w porównaniu z zastosowaniem go w dawkach zredukowanych. Porównując szybkość zanikania bromoksynilu łączonego z terbutylazyną, można zauważyć, że chociaż charakter przebiegu dynamiki zanikania był bardzo podobny, to zanikanie bromoksynilu w mieszaninie w porównaniu do substancji stosowanej samodzielnie było znacznie szybsze. Obserwowane różnice szybkości migracji badanych substancji potwierdzają doniesienia literaturowe dotyczące wpływu budowy związku na jego zachowanie w środowisku (Kotoula-Syka i wsp. 1993). Poziom pozostałości substancji czynnych w glebie w momencie zbioru kukurydzy osiąga przeciętnie wartość rzędu 0,002 mg/kg, tj. 2\% od początkowego stężenia, co może stwarzać zagrożenia dla upraw następczych w płodozmianie, zwłaszcza zbóż. W przypadku zastosowania mieszaniny herbicydów Zeagran 340 EC i Nikosulfuron 040 SC z adiuwantem już po 8 tygodniach od aplikacji nie wykrywano w próbkach glebowych żadnych pozostałości bromoksynilu, niezależnie od użytych dawek. Natomiast w przypadku zastosowania bromoksynilu samodzielnie, jego pozostałości w momencie zbioru kukurydzy były najwyższe spośród badanych próbek.

\section{Wnioski / Conclusions}

1. Bromoksynil zastosowany w mieszaninie $z$ terbutylazyną i nikosulfuronem, zarówno w dawce podstawowej, jak i obniżonej o 33\% (+ adiuwant) wykazał lepsze działanie chwastobójcze niż aplikowany samodzielnie oraz w mieszaninie tylko z nikosulfuronem. 
2. Najwyższy poziom pozostałości bromoksynilu w próbkach glebowych pobieranych w okresie ośmiu tygodni po zabiegu stwierdzono dla obiektu, na którym substancję tę zastosowano z nikosulfuronem w dawce pełnej. Po tym czasie ilość pozostałości była zbliżona do mieszaniny bromoksynilu z nikosulfuronem w dawce zredukowanej.

3. Bromoksynil najszybciej uległ rozkładowi w glebie na poletkach traktowanych mieszaniną trójskładnikową, tj. bromoksynil + terbutylazyna + nikosulfuron $(+$ adiuwant) w dawce zredukowanej o $33 \%$.

\section{Literatura / References}

Abdin O.A., Zhou X.M., Cloutier D., Coulman D.C., Faris M.A., Smith D.L. 2000. Cover crops and interrow tillage for weed control in short season maize (Zea mays L.). European Journal of Agronomy 12 (2): 93-102. DOI: 10.1016/s1161-0301(99)00049-0

Adamczewski K., Kierzek R. 2011. Problem odporności chwastów na herbicydy w Polsce. [Weed resistance problem in Poland]. Progress in Plant Protection/Postępy w Ochronie Roślin 51 (4): 1665-1674.

Domaradzki K. (red.). 2001. Metodyka doświadczeń biologicznej oceny herbicydów, bioregulatorów i adiuwantów. Cz. 1. Doświadczenia polowe. Instytut Uprawy Nawożenia i Gleboznawstwa - Państwowy Instytut Badawczy, Puławy, 167 ss.

Ehsas J., Desai L.J., Ahir N.B., Joshi J.R. 2016. Effect of integrated weed menagment on growth, yield, yield attributes and weed parameters on summer maize (Zea mays L.) under South Gujarat Condition. International Journal of Science, Environment and Technology 5 (4): 2050-2056. DOI: 10.20546/ijcmas.2018.708.308

Furlan L., Vasileiadis V.P., Chiarini F., Huiting H., Leskovsek R., Razinger J., Holb I.J., Sartori E., Urek G., Verschwele A., Benvegnu I., Sattin M. 2017. Risk assessment of soil-pest damage to grain maize in Europe within the Framework of Integrated Pest Menagement. Crop Protection 97: 52-59. DOI: 10.1016/j.cropro.2016.11.029

Gołębiowska H. 2011. Różnorodność zbiorowisk chwastów kukurydzy w zależności od zmianowania roślin i uprawy roli. [Diversity of weed infestation depending on maize cropping system]. Acta Scientarium Polonorum, Sectio Agricultura 10 (1): 13-23.

Hruszka M. 2003. Efektywność proekologicznych i chemicznych sposobów regulacji zachwaszczenia w zasiewach kukurydzy pastewnej. Cz. I. Wpływ zastosowanych zabiegów na stan i stopień zachwaszczenia łanu kukurydzy pastewnej. [Effectiveness of pro-ecological and chemical methods of weed control in maize. P. I. The effect of the applied methods on the state and degree of weeds in maize]. Zeszyty Problemowe Postępów Nauk Rolniczych 490 (1): 81-89.

Idziak R., Woźnica Z. 2016. Wpływ dawki oraz terminu stosowania mieszaniny mezotrionu z nikosulfuronem i adiuwantami na efektywność odchwaszczania kukurydzy. [Weed control efficacy of nicosulfuron plus mesotrione in maize as influenced by rate, application time, and adjuvants]. Fragmenta Agronomica 33 (1): 30-37.

Kalitowska O., Kucharski M. 2017. Wpływ metali ciężkich na rozkład bromoksynilu w glebie z Legnicko-Głogowskiego Okręgu Miedziowego. [Influence of heavy metals on bromoxynil decay in soil from Legnica-Głogów Copper District]. Progress in Plant Protection 57 (1): 61-65. DOI: 10.14199/ppp-2017-009

Kotoula-Syka E., Eleftherohorinis I.G., Gagianas A.A., Sficas A.G. 1993. Phytotoxicity and persistence of chlorsulfuron, metsulfuronmethyl, triasulfuron and tribenuron-methyl in three soils. Weed Research 33 (5): 355-367. DOI: 10.1111/j.1365-3180.1993. tb01951.x

Kucharski M., Sadowski M., Kieloch R. 2012. Adiuwanty w zabiegach przedwschodowych - wpływ na skuteczność diflufenikanu i jakość ziarna pszenicy ozimej. [Adjuvants in preemergence application - influence on diflufenican efficacy and quality of winter wheat grain]. Progress in Plant Protection/Postępy w Ochronie Roślin 52 (1): 51-54. DOI: 10.14199/ppp-2012-010

Kucharski M., Sekutowski T. 2007. Wpływ rotacji herbicydów na liczebność chwastów odpornych w monokulturze kukurydzy. [Influence of herbicides rotation on number of resistant weeds in monoculture of maize crop]. Inżynieria Rolnicza 3 (91): 129-133.

Pannacci E. 2016. Optimalization of foramsulfuron doses for pest-emergence weed control in maize (Zea mays L.). Spanish Journal of Agricultural Research 14 (3): 1-9. DOI: 10.5424/sjar/2016143-9436

Pannacci E., Onofri A., Covarelli G. 2006. Biological activity, availability and duration of phytotoxicity for imazamox in four different soils of central Italy. Weed Research 46 (3): 243-250. DOI: 10.1111/j.1365-3180.2006.00503.x

Pruszyński S., Mrówczyński M., Adamczewski K., Banaszak H., Bubniewicz P., Głazek M., Jańczak C., Juszczak M., Korbas M., Paradowski A., Pietryga J., Miziniak W., Piszczek J., Praczyk T., Seta G., Stachecki S., Stobecki S., Wachowiak H., Wachowiak M. 2002. Łączne stosowanie agrochemikaliów. Instytut Ochrony Roślin - Państwowy Instytut Badawczy, Poznań: 91-104.

Rozporządzenie MRiRW z dnia 18.04.2013 r. w sprawie wymagań integrowanej ochrony roślin (Dz. U. z 2013 r., poz. 505).

Rozporządzenie Parlamentu Europejskiego i Rady (WE) nr 1107/2009 z dnia 21 października 2009 r. dotyczące wprowadzania do obrotu środków ochrony roślin i uchylającego dyrektywy Rady 79/117/EWG i 91/414/EWG (Dz. Urz. UE L 309 z 24.11.2009, str. 1, z późniejszymi zmianami).

Sadowski J. 2009. Środowiskowe skutki pozostałości herbicydów. Materiały szkoleniowe nr 94. Instytut Uprawy Nawożenia i Gleboznawstwa - Państwowy Instytut Badawczy, Puławy, 61 ss. ISBN 978-83-7562-018-4.

Szulc P., Jagła M., Nowosad K., Bocianowski J., Olejarski P. 2017. Path analysis in assessment of cause and effect dependencies of yield structure components in maize cultivars differing in genetic profiles. Fresenius Environmental Bulletin 26 (12): 7309-7318.

Týr Š. 2015. Weed infestation maize in sustainable agricultural systems. Research Journal of Agricultural Science 47 (1): $234-242$.

Vasileiadis V.P., Van Dijk W., Verschwele A., Holb I.J., Vamos A., Urek G., Leskovsek R., Furlan L., Sattin M. 2016. Farm-scale evaluation of herbicide band application integrated with inter-row mechanical weeding for maize production in four European regions. Weed Research 56 (4): 312-322. DOI: 10.1111/wre.12210 